\title{
Congressional Trends to Tax and Spend: Examining Fiscal Voting Across Time and Chamber
}

\author{
Edward J. López* \\ Scholar in Residence, Liberty Fund, Inc. and Associate Professor of Law and Economics, San José State University, One \\ Washington Square, San José, CA 95192-0114, USA
}

\begin{abstract}
This note presents data on Congressional fiscal policy by party and chamber, using the National Taxpayers Union annual vote index for 1979-2002. NTU scores are presented with and without adjusting for interchamber and intertemporal movements of the policy space over which the scores are calculated. Results indicate that the parties and chambers are much more stable over time, and exhibit a slighter liberal trend, when accounting for movements in the policy space. The adjusted scores also indicate less change during fiscal milestones.
\end{abstract}

JEL Subject Descriptors: D720; H300; H500; H600.

Keywords: Fiscal policy, legislator voting, ideal point estimation.

\section{INTRODUCTION}

Congress plays a pivotal role in the fiscal outcomes that motivate a range of issues in public finance and political economics. Regarding budget deficits and public debt, for example, scholars and commentators routinely point out that the president sets the budget along with Congress. However, when making comparisons over time (e.g., growing deficits) attention is usually focused on the executive branch and external circumstances (e.g., war, natural disaster, financial bailout). Observers are inclined also to decry certain budget items that seem to serve narrow or low-priority interests such as pork-barrel projects. In contrast, relatively little attention is given to Congress' tendencies toward more or less fiscal restraint over time. Certain studies have examined voting on fiscal issues by individual legislators over their careers (Aka et al. 1996; Reed et al. 1998), but there is a dearth of work examining the aggregate fiscal preferences of parties and chambers. This note presents basic data useful for incorporating congressional fiscal policy preferences into research in economics and politics.

The data comes from the 1979-2002 annual index of roll call votes compiled by the National Taxpayers Union, a nonprofit research and advocacy organization based in Washington, D.C. Due to the nature of calculating NTU scores, transformations must be made in order to draw intertemporal and interchamber comparisons ${ }^{1}$. In general, the adjusted data indicate much less volatility and a slighter liberal trend than do the nominal data. In addition, during fiscal milestones the adjusted scores indicate less pronounced changes in Congress' fiscal policy position.

*Address correspondence to this author at the Scholar in Residence, Liberty Fund, Inc. and Associate Professor of Law and Economics, San José State University, One Washington Square, San José, CA 95192-0114, USA; Email: edward.lopez@sjsu.edu

${ }^{1}$ The transformation is analogous to adjusting nominal data for inflation over time and for cross-sectional purchasing power differences.

\section{DESCRIPTION OF THE DATA}

The NTU incorporates every vote that has an effect on federal spending, taxes, federal debt, or certain types of regulation. Each vote is assigned a weight based on the magnitude of its fiscal effect. A legislator's NTU score in a given year is the weighted frequency with which he/she voted to reduce, or not to increase, spending or taxes. The score's range is 0 to 100 , with a higher score indicating more fiscal restraint in voting. Table $\mathbf{1}$ provides a summary of how NTU scores are calculated each year. In an average year, the scores include 197 House votes and 153 Senate votes. Subjective weighting of the votes began in 1985 . The current sample includes a score for every representative and senator during the 24-year period considered, amounting to 12,810 scores $^{2}$.

\section{RESULTS: INITIAL VIEW}

Fig. (1) shows mean nominal NTU scores by chamber and party. Several things are noteworthy. First, the House and Senate are remarkably close together; neither seems to be more or less fiscally conservative or liberal. Second, Republicans score consistently higher than Democrats in both the House and Senate (although in the 1980s the parties were close in the Senate). Fig. (1) also presents party polarization (Republican minus Democrat mean), confirming scholarly and popular wisdom that the parties are becoming more polarized (Poole and Rosenthal 1991; Grofman et al. 2001; López and Ramírez 2004). In the Senate, fiscal polarization increases five-fold between 1991 and 1993, and increases further from there. House polarization increases with similar magnitude beginning in 1989, though it settles down after 1995. Next, these figures seem to reflect certain milestones in recent congressional history. For example, the 1994 "Republican revolution" is evident in the House and Senate panel, and for Republicans there was some build up

${ }^{2} \mathrm{~A}$ surprisingly small number of cells (30) are missing data due to vacancies or excessive absenteeism, in which case the NTU does not record a score. 
Table 1. Basis for Calculating NTU Scores: 1979-2002

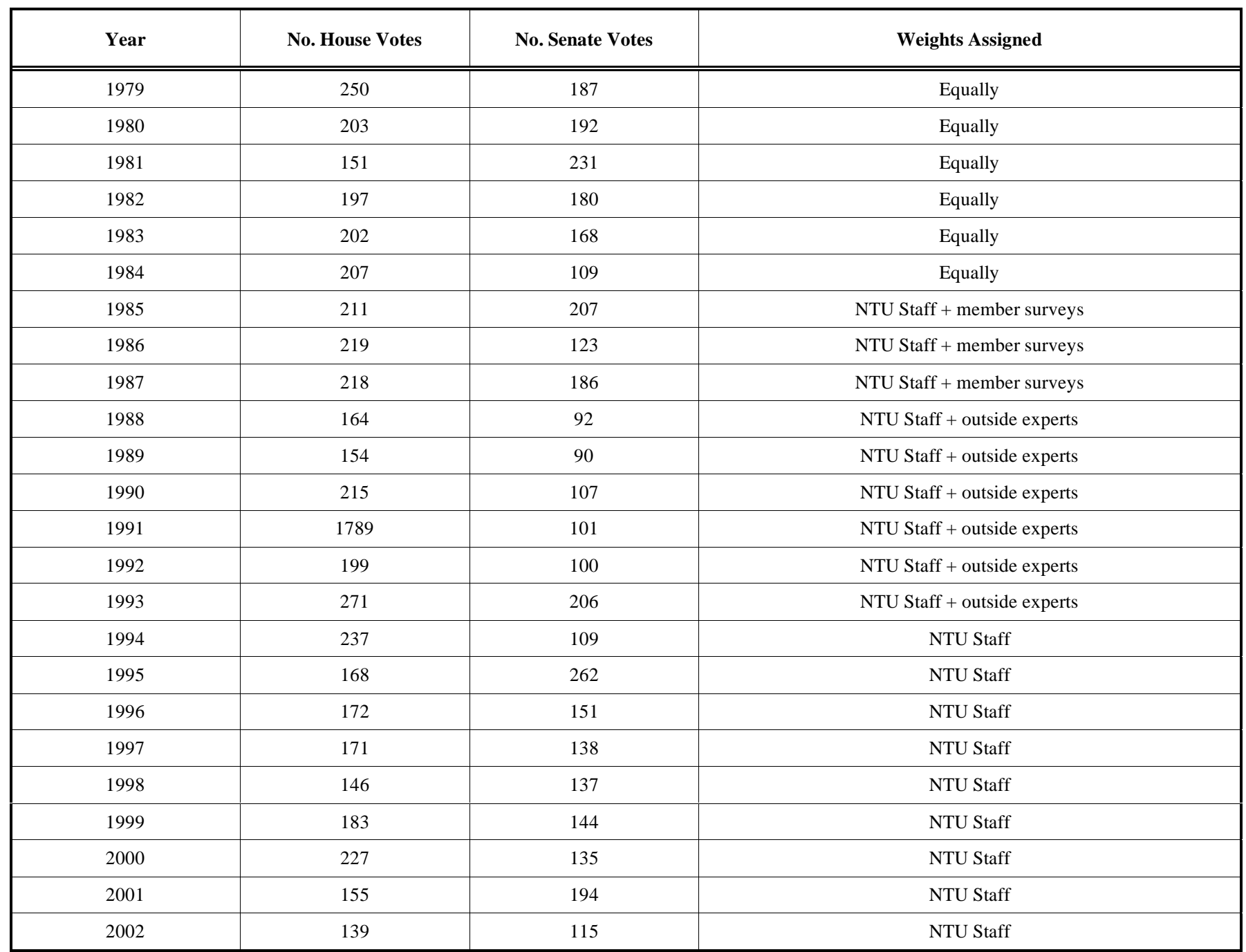

Source: National Taxpayers Union, annual congressional voting studies, 1979-2002.

beginning in 1991. However, the figures also suggest puzzling changes occurring without a fiscal milestone. For example, in 1988, both the House and Senate appear to drop significantly toward fiscal largess. But there was no major tax bill in that year, and the budget deficit in nominal dollars was already shrinking from its high in 1986. It is not clearfrom President Reagan's 1988 budget proposal, for example - that the stock market crash of 1987 led to major fiscal policy changes. Furthermore, nothing in the 1988 study by NTU indicates a rationale for why the scores are much lower in that year than in neighboring years. Such apparent anomalies may be simply due to the fact that hundreds of votes are considered, and no single issue is given sufficient weight in order to affect appreciably even an individual's score, much less a party or chamber mean. However, there is a substantive issue in making these comparisons across time and chamber.

\section{SHIFTING AND STRETCHING THE POLICY SPACE: RATIONALE AND METHODOLOGY}

Vote indices such as NTU scores are based on an underlying policy space determined by the set of votes used to calculate the index. The set of fiscal issues brought to floor votes changes from year to year and differs across chambers in a given year-both of which are evident in Table 1. Furthermore, the subjective weighting process also changes over time due to the addition of new staff assigning the weights under evolving procedures. These aspects together mean that the underlying space is not stable over years or between House and Senate. According to Groseclose, Levitt, and Snyder (1999), the underlying policy space "shifts" and "stretches" when the set of votes changes. This can cause spurious changes in legislators' vote scores.

To illustrate the problem specifically for NTU scores, assume each representative and senator has an ideal policy outcome over all conceivable fiscal issues. Assume further that ideal points are fixed, so that a measure of each member's fiscal policy position should remain unchanged over time. If the set of votes used to compute the index shifts, members' scores will change even though their true positions are fixed. Suppose, for example, that from period $t$ -1 to period $t$ the chair of the budget committee changes hands from a fiscal conservative to a fiscal liberal, so that a series of larger than previous spending increases are reported 

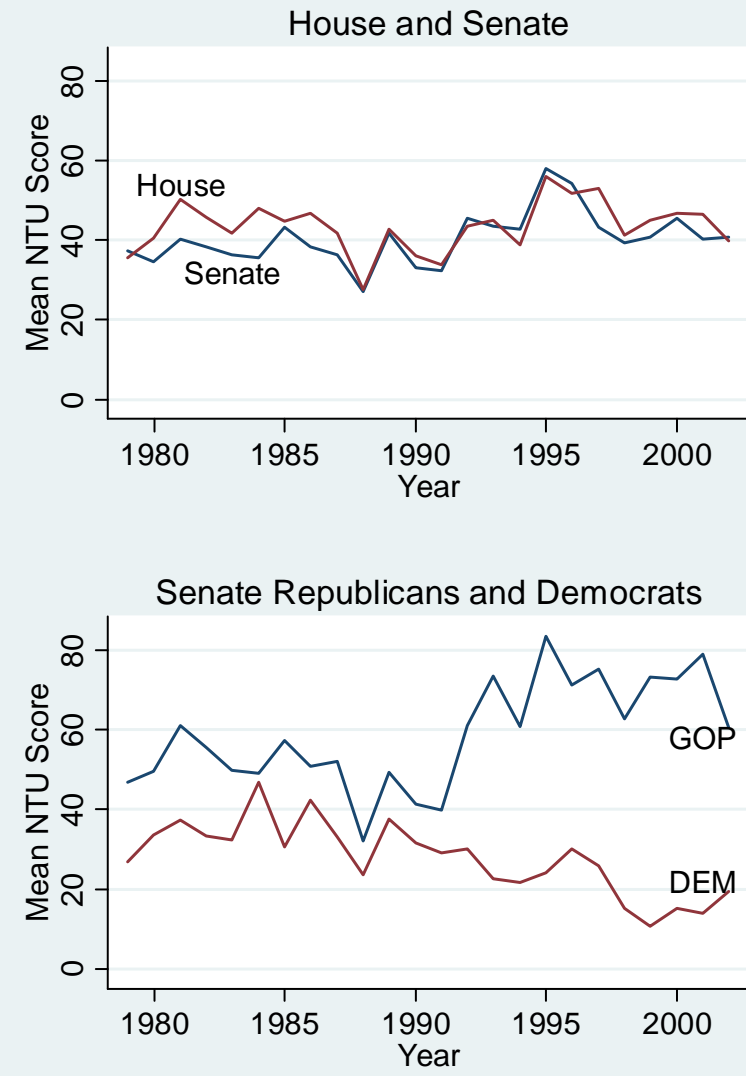

Fig. (1). Nominal NTU Scores by Chamber, Party, and Polarization.

to the floor. Fewer members will vote for these measures than previously, and those who vote against will receive greater NTU scores, so the chamber will appear to become more fiscally restrained in period $t$. Following Groseclose, Levitt, and Snyder (1999), this spurious increase can be corrected by a simple counter shift parameter-call it $a_{t}-$ subtracted from a member's score in magnitude commensurate with the degree of the shift in policy space.

A similar problem can occur if the space stretches. Suppose a new presidency ushers in a period of divided government, and perhaps the spending priorities differ greatly between congressional leaders and the administration - or perhaps for deficit reduction one group wants to increase taxes and the other to decrease spending. The set of fiscal policy floor votes under the new presidency will have greater variance. Members away from the center will change votes, and the variance of NTU scores will diminish. Depending on majority-minority shares of seats and party cohesion, this could lead to major changes in party and chamber means (Merrill et al. 1999). Meanwhile no legislator's ideal point has moved. Again following Groseclose, Levitt, and Snyder (1999), the scores can be adjusted by a stretch parameter-call it $b_{t}$-which is inversely related to the magnitude of the stretch in scale ${ }^{3}$. The shift and stretch adjustments are effectuated by a linear

${ }^{3}$ It is not necessary to assume legislators' policy positions are fixed. If the scale shifts and/or stretches relative to even a moving ideal point, the unadjusted NTU scores will still overstate the degree of movement in the ideal point.
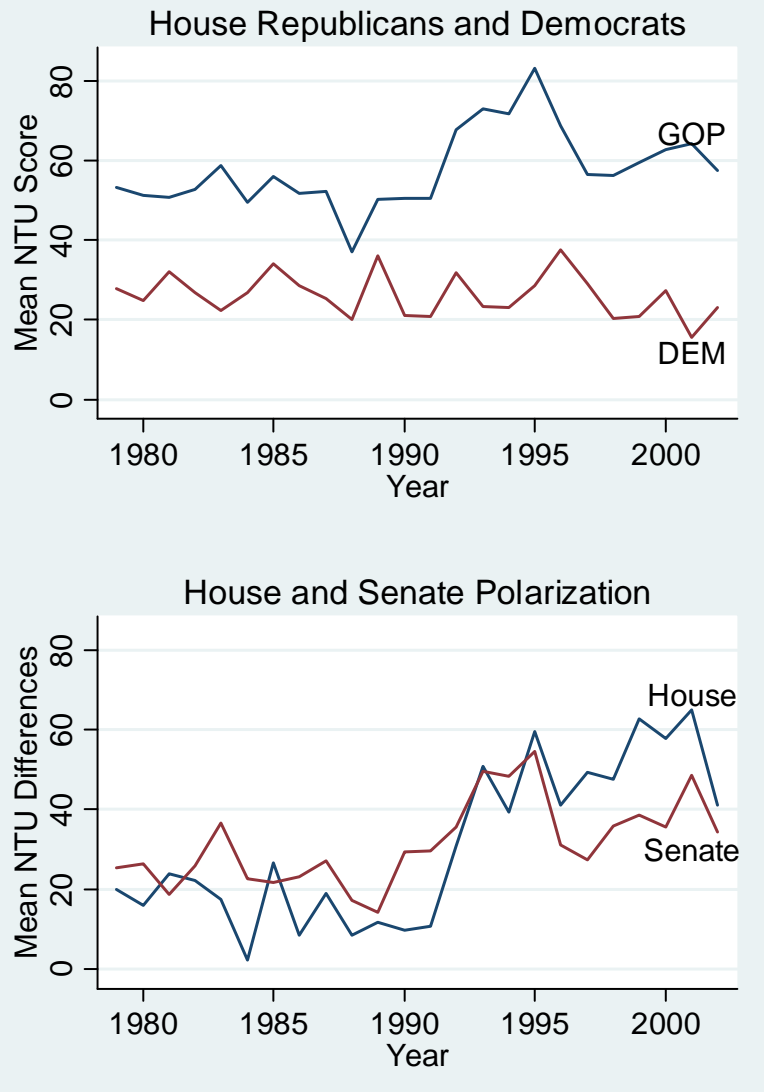

transformation: if the $k^{\text {th }}$ member in chamber $i$ has NTU score $y_{k i t}$ in period $t$, the adjusted NTU score is $\hat{y}=\frac{y_{k i t}-\hat{a}_{t}}{\hat{b}_{t}}$, where the parameter estimates $\hat{a}_{i t}$ and $\hat{b}_{i t}$ for each chamberyear are obtained using maximum likelihood as detailed in Groseclose, Levitt, and Snyder (1999). The NTU parameter estimates for House and Senate appear in the Appendix ${ }^{4}$.

\section{RESULTS: ADJUSTED VIEW}

Fig. (2) contains the nominal and adjusted mean NTU scores for chambers over time. Compared to nominal, the adjusted scores exhibit a remarkable degree of stability in both the House and Senate ${ }^{5}$. Thus, seemingly large year-toyear changes in the nominal data are attributable mostly to movements of the policy space. Notice that the 1988 "dip" does not appear for either House or Senate; thus, Congress' apparent shift to fiscal largess was actually a conservative shift of the issue set. In the House there is one relatively large upward movement following the 1994 elections. The increase from 1994 to 1995 is more than 10 percent of the

${ }^{4}$ Tim Groseclose uploaded the program code for conducting the estimations in an old version of Matlab. I obtained the estimates in the Appendix to this paper using an update to the older code for use in a newer version of Matlab. I first replicated Groseclose's estimates for ADA scores, then proceeded to estimate the parameters for the NTU data. Full details are available on request.

${ }^{5}$ This also contrasts with a high degree of fluctuation in both nominal and adjusted measures of voting on a broader issue set, such as ADA scores (Groseclose et al. 1999; Grofman et al. 2001). 


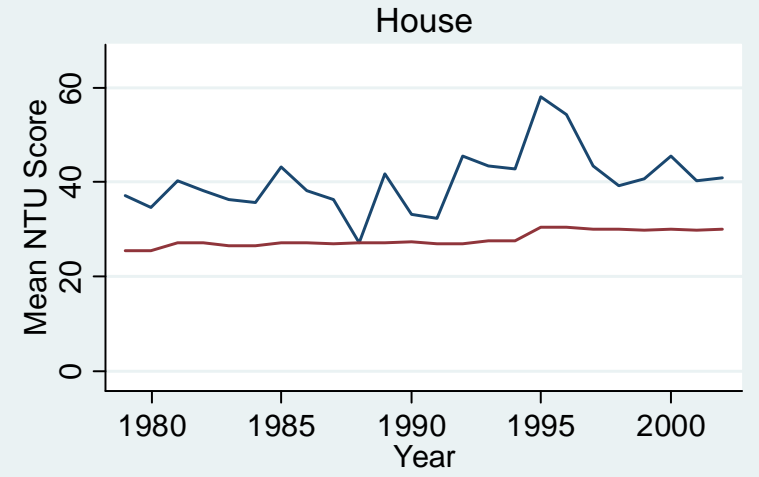

House Polarization

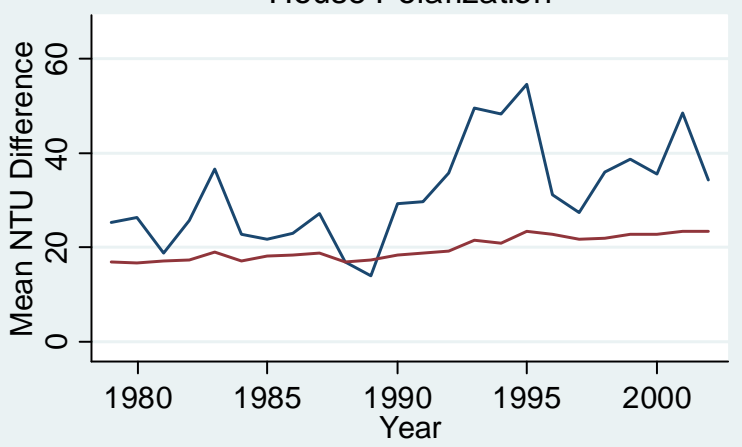

Note: Less volatile lines are the adjusted scores.

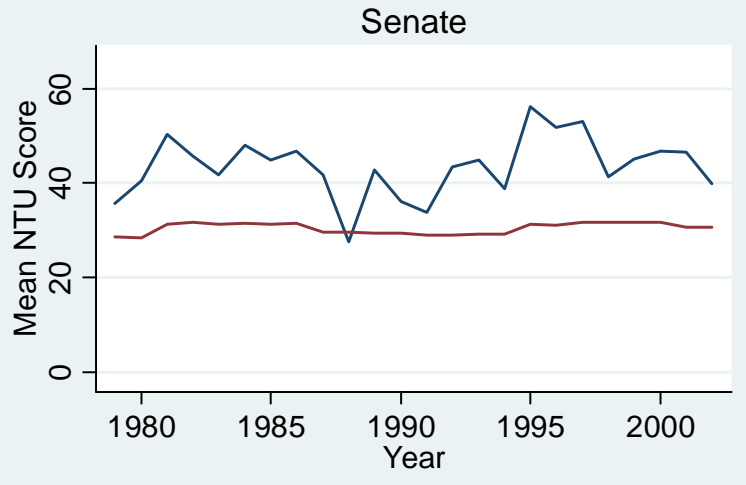

Senate Polarization

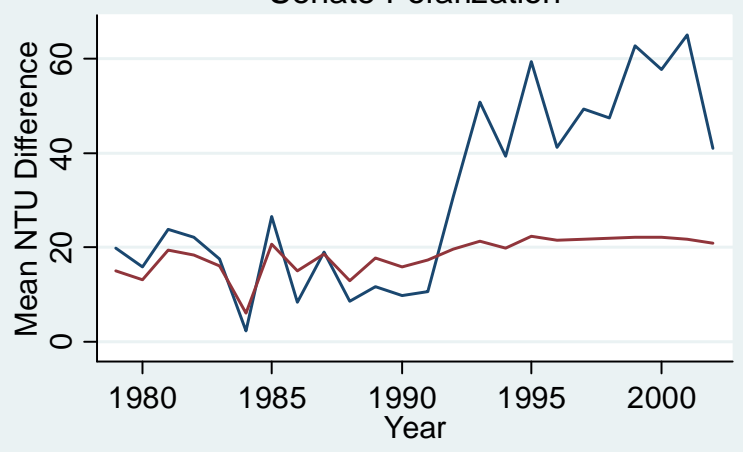

Fig. (2). Nominal and Adjusted NTU Scores by Chamber.

mean and is a larger change than in any other year. The Senate, while also stable over the long term, appears to be relatively conservative during most of the Reagan years, then dips down between 1987 and 1994, and then again reflects greater fiscal restraint with the Republican majority that began in 1995. Overall, the House and Senate are very close together, with the Senate being slightly more fiscally conservative in most years. The effect of the shift and stretch parameters can also be seen by comparing the year-to-year changes in the nominal and adjusted scores. For example, from 1994 to 1995, the nominal House mean increased by 15.12 percent, but the real score increased by only 10.2 percent. Thus, the movement of the policy space explains roughly 4.9 percent of the change that year.

The adjusted scores also indicate much less polarization than do the nominal scores, particularly after about 1990. While there are certainly some upward ticks in both the House and Senate, a great deal of the apparent polarization can be attributed to changes in the issue space. In 1993 through 1995 in particular, the $b_{t}$ parameter estimates in the Appendix suggest that the set of votes brought to the House floor had greater variance than in the preceding and following years. This would explain the dramatic increase in polarization within the nominal scores, but a smaller increase in the adjusted scores.

The individual parties are profiled in Fig. (3). Here again we see that the adjusted scores show greater stability, but
Republicans still become slightly more fiscally conservative over time while Democrats move slightly opposite. Interestingly, the 1988 "dip" also involved a move of the senate parties to the center. Republicans show an 8 percent decrease (toward fiscally liberal) followed by a 6.5 percent increase in 1989, and Democrats show a 1.2 percent increase followed by an almost 10 percent decrease in 1989. The previous presidential election year, 1984, saw an even greater decrease in Senate fiscal polarization.

\section{DISCUSSION AND CONCLUSION}

The discussion in this note only scratches the surface. The data here can be used by economists to analyze issues such as debt and deficits, growth in government, fiscal federalism, and macroeconomic policy, as well as presidential-congressional relations. Political scientists will also be interested in the shift and stretch parameter estimates themselves-for example, in models of agenda setting power. A natural extension is to examine nominal and adjusted NTU scores among congressional leaders, since their fiscal policy positions largely determine the issue space. In addition, considering medians rather than means may afford greater applicability in spatial models based on median tendencies. Also, since growing deficits have become more of an issue of debate under President George W. Bush, it will be of interest to incorporate data through 2008, and calculate the adjusted scores, once the data become available. Finally, previous econometric results 
House

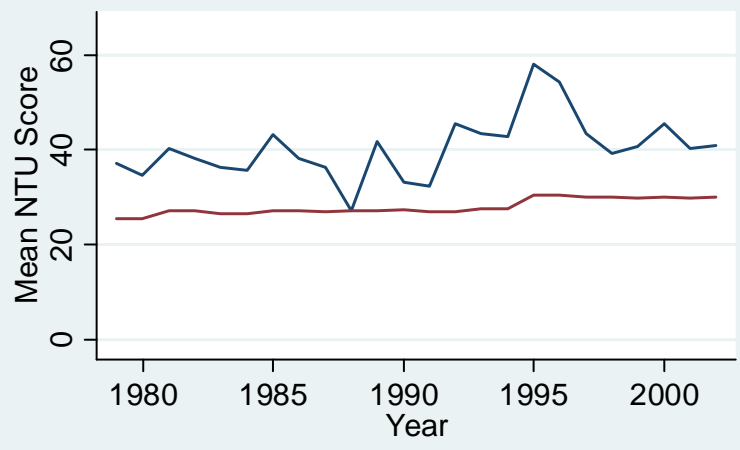

House Polarization

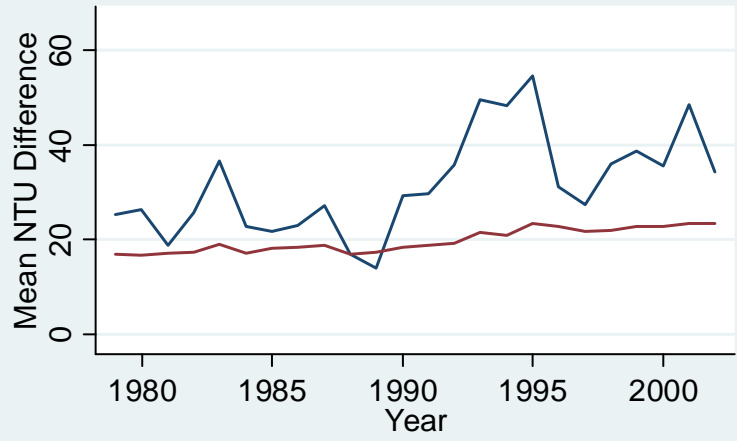

Senate

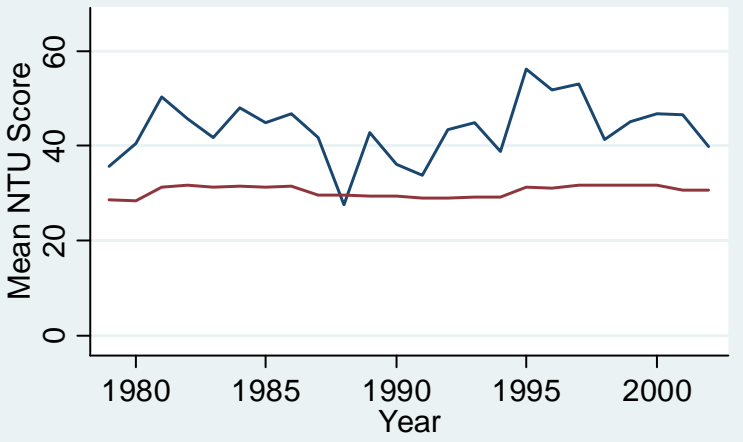

Senate Polarization

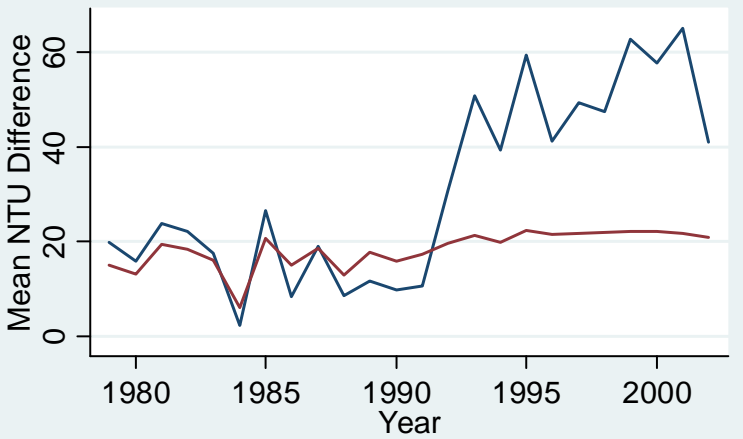

Note: Less volatile lines are the adjusted scores.

Fig. (3). Nominal and Adjusted NTU Scores by Party.

using nominal NTU scores (e.g., Aka et al. 1996, Reed et al. 1998) could be revisited to investigate whether adjusting the scores alter results.

\section{ACKNOWLEDGMENTS}

For helpful comments, I thank Gregory Dybalski and Joseph McGarrity. For excellent research assistance, I thank Anna C. Sampson.

\section{REFERENCES}

[1] Aka, A., Reed, W.R., Schansberg, D. E., \& Zhu, Z. (1996). Is There a 'Culture of Spending' in Congress? Economics and Politics, 8, 191-212.

[2] Grofman, B., Koetzle, W., Merrill, S., \& Brunell, T. (2001). Changes in the Location of the Median Voter in the U.S. House of Representatives, 1963-1996. Public Choice, 106(3/4), 221-232.
[3] Groseclose, T., Levitt, S.D., \& Snyder, J.M. Jr. (1999). Comparing interest group scores across time and chambers: Adjusted ADA scores for the U.S. Congress. American Political Science Review, 93(1), 33-50.

[4] López, E.J. \& Ramírez, C.D. (2004). Party Polarization and the Business Cycle in the United States. Public Choice, 121(3), 413430 .

[5] Merrill, S., Grofman, B., Brunnell, T., \& Koetzle, W. (1999). The Power of Ideologically Concentrated Minorities. Journal of Theoretical Politics, 11(1), 57-74.

[6] Poole, K.T., \& Rosenthal, H. (1991). Patterns of Congressional Voting. American Journal of Political Science, 35(1), 228-78.

[7] Reed, W.R., Schansberg, D.E., Wilbanks, J., \& Zhu, Z. (1998). The Relationship Between Congressional Spending and Tenure with An Application to Term Limits. Public Choice, 94, 85-104. 
Appendix: Shift and Stretch Parameter Estimates for Adjusting NTU Scores Across Time and Chamber

\begin{tabular}{|c|c|c|c|c|}
\hline Year & $\hat{a}$ & $\hat{b}$ & $\hat{a}$ & $\hat{b}$ \\
\hline 1980 & -5.7617 & 1.5826 & 5.8251 & 1.217 \\
\hline 1981 & 10.7679 & 1.0884 & 11.938 & 1.2213 \\
\hline 1983 & -14.5767 & 1.9186 & 7.82 & 1.0833 \\
\hline 1984 & 0.7821 & 1.3174 & 36.1213 & 0.3801 \\
\hline 1985 & 10.875 & 1.1933 & 4.4456 & 1.2889 \\
\hline 1989 & 19.7176 & 0.814 & 23.3209 & 0.6649 \\
\hline 1990 & -10.0705 & 1.5875 & 18.0477 & 0.612 \\
\hline 1991 & -9.7982 & 1.5678 & 16.0667 & 0.6093 \\
\hline 1992 & -4.167 & 1.8525 & -2.0819 & 1.5706 \\
\hline 1993 & -19.9375 & 2.2963 & -24.7309 & 2.3754 \\
\hline 1994 & -21.1225 & 2.3141 & -19.1838 & 1.9775 \\
\hline 1995 & -12.946 & 2.3275 & -27.5811 & 2.6662 \\
\hline 2001 & -21.3921 & 2.0699 & -45.1818 & 2.9878 \\
\hline 2002 & -2.9647 & 1.4622 & -20.4605 & 1.9688 \\
\hline
\end{tabular}

Notes: $\hat{a}$ is the shift parameter and is $\hat{b}$ the stretch parameter. 